\title{
Palmitoylethanolamide controls reactive gliosis and exerts neuroprotective functions in a rat model of Alzheimer's disease
}

\author{
C Scuderi ${ }^{\star, 1}$, C Stecca ${ }^{1}$, M Valenza ${ }^{2}$, P Ratano ${ }^{1}$, MR Bronzuoli ${ }^{1}$, S Bartoli ${ }^{1}$, L Steardo ${ }^{3}$, E Pompili ${ }^{4}$, L Fumagalli ${ }^{4}$, P Campolongo ${ }^{1}$ \\ and L Steardo ${ }^{1}$
}

Given the complex heterogeneity of pathological changes occurring in Alzheimer's disease (AD), any therapeutic effort absolutely requires a multi-targeted approach, because attempts addressing only a single event may result ineffective. Palmitoylethanolamide (PEA), a naturally occurring lipid amide between palmitic acid and ethanolamine, seems to be a compound able to fulfill the criteria of a multi-factorial therapeutic approach. Here, we describe the anti-inflammatory and neuroprotective activities of systemic administration of PEA in adult male rats given intrahippocampal injection of beta amyloid 1-42 (A $\beta$ 1-42). Moreover, to investigate the molecular mechanisms responsible for the effects induced by PEA, we co-administered PEA with the GW6471, an antagonist of peroxisome proliferator-activated receptor- $\alpha$ (PPAR- $\alpha$ ). We found that $A \beta$ 1-42 infusion results in severe changes of biochemical markers related to reactive gliosis, amyloidogenesis, and tau protein hyperphosphorylation. Interestingly, PEA was able to restore the A $\beta$ 1-42-induced alterations through PPAR- $\alpha$ involvement. In addition, results from the Morris water maze task highlighted a mild cognitive deficit during the reversal learning phase of the behavioral study. Similarly to the biochemical data, also mnestic deficits were reduced by PEA treatment. These data disclose novel findings about the therapeutic potential of PEA, and suggest novel strategies that hopefully could have the potential not just to alleviate the symptoms but also to modify disease progression.

Cell Death and Disease (2014) 5, e1419; doi:10.1038/cddis.2014.376; published online 11 September 2014

\begin{abstract}
Alzheimer's disease (AD) is the most common late-onset and progressive neurodegenerative disorder. ${ }^{1}$ It is characterized by progressive dementia including episodic memory impairments and involvement of other cognitive domains and skills. ${ }^{2}$ Although senile plaques (SP) and neurofibrillary tangles (NFTs) are considered pathognomic, ${ }^{3}$ the concept that these are the only significant pathological changes occurring in AD brain is misleading. In fact, both in vitro and in vivo findings have demonstrated that beta amyloid $(\mathrm{A} \beta)$ fragments promote a marked neuroinflammatory response, accounting for the synthesis of different cytokines and pro-inflammatory mediators. ${ }^{4} \mathrm{~A}$ chronic inflammation goes beyond physiological control and eventually detrimental effects override the beneficial effects. In fact, after their release, pro-inflammatory signaling molecules may act autocrinally to self-perpetuate reactive gliosis and paracrinally to kill neighboring neurons, thus amplifying the neuropathological damage. Once started, the inappropriate and prolonged inflammatory process may
\end{abstract}

contribute independently to neural dysfunction, cell death, and disease progression. ${ }^{5,6}$ Besides the sustained production of pathogenic substances, astrocytes fail to provide their neurosupportive functions, making neurons more vulnerable to toxic molecules. ${ }^{7}$ Therefore, targeting neuroinflammation might be an effective therapeutic strategy in AD. ${ }^{8-11}$

At present, no therapies in clinical use are able to effectively impact the disease course. Therefore, new drugs able to simultaneously ameliorate the numerous pathogenic mechanism involved in AD are therapeutically promising.

Palmitoylethanolamide (PEA) has attracted much attention for its proven anti-inflammatory and neuroprotective properties reported in many neuropathological conditions other than AD. PEA, a naturally occurring amide of ethanolamine and palmitic acid, is a lipid messenger that mimics several endocannabinoid-driven actions, even though it does not bind to cannabinoid receptors. ${ }^{12-20}$ PEA is abundant in the central nervous system (CNS) and it is conspicuously produced by

\footnotetext{
${ }^{1}$ Department of Physiology and Pharmacology 'Vittorio Erspamer'-SAPIENZA University of Rome, P.le A. Moro, Rome 5-00185, Italy; ${ }^{2}$ Laboratory of the Biology of Addictive Diseases-The Rockefeller University, 1230 York Avenue, New York, NY 10065, USA; ${ }^{3}$ Department of Psychiatry-University of Naples SUN, Largo Madonna delle Grazie, Naples 1-80138, Italy and ${ }^{4}$ Department of Anatomy, Histology, Forensic Medicine and Orthopedics-SAPIENZA University of Rome, Via A. Borelli 50, Rome 00161, Italy

${ }^{*}$ Corresponding author: C Scuderi, Department of Physiology and Pharmacology 'Vittorio Erspamer'-SAPIENZA, University of Rome, P.le Aldo Moro, 5, Rome 00185, Italy. Tel: +39 6 49912713; Fax: +39 6 49912480; E-mail: caterina.scuderi@uniroma1.it

Abbreviations: AD, Alzheimer disease; A $1-42$, beta amyloid 1-42; PEA, palmitoylethanolamide; SP, senile plaques; NFTs, neurofibrillary tangles; CNS, central nervous system; PPAR- $\alpha$, peroxisome proliferator-activated receptor-alpha; GW6471, N-((2S)-2-(((1Z)-1-methyl-3-oxo-3-(4-(trifluoromethyl)phenyl)prop-1-enyl)amino)3-(4-(2-(5-methyl-2-phenyl-1,3-oxazol-4-yl)ethoxy)phenyl)propyl)propanamide; GFAP, glial fibrillary acidic protein; RT-PCR, reverse transcription-polymerase chain reaction; ELISA, enzyme-linked immunosorbent assay; aCSF, artificial cerebral spinal liquid; IL-1 $\beta$, interleukin-1beta; TNF- $\alpha$, tumor necrosis factor-alpha; NF- $\kappa B$, nuclear factor $\kappa \mathrm{B}$; COX-2, cyclooxygenase-2; iNOS, inducible nitric oxide synthase; BACE1, beta secretase; APP, amyloid precursor protein; GSK3 $\beta$, glycogen synthase kinase 3 beta; Dkk-1, Dickopff-1; p-tau, phosphorylated tau; MAP-2, microtubule-associated protein-2; MWM, Morris water maze; DAPI, 4',6-diamidino-2phenylindole; OD, optical density; ANOVA, analysis of variance; S.E.M., standard error of the mean

Received 25.6.14; accepted 21.7.14; Edited by A Verkhratsky
} 
glial cells. ${ }^{14,15}$ Many of its beneficial properties have been considered to be dependent on the activation of the peroxisome proliferator-activated receptor-alpha (PPAR- $\alpha) .{ }^{12,21}$ Recent reports from our group showed the ability of PEA to attenuate in vitro the $\mathrm{A} \beta$-induced upregulation of a wide range of inflammatory mediators by interacting at the PPAR- $\alpha$ nuclear site. ${ }^{22,23}$ Both PPAR- $\alpha$ and PEA are clearly detected in the CNS and their expression may largely change during pathological conditions. ${ }^{24}$ It has been observed that $\mathrm{A} \beta$ significantly blunts PPAR- $\alpha$ in primary rat astrocytes, suggesting the possibility that the downregulation of this receptor may represent one of the molecular mechanisms by which $\mathrm{A} \beta$ induces astrocyte activation and possibly exerts toxicity. In addition, PEA is able to reverse the downregulation of PPAR- $\alpha$ induced by $\mathrm{A} \beta$, thus mitigating the overexpression of proinflammatory molecules and signals. ${ }^{25}$

Therefore, we explored the anti-inflammatory and neuroprotective effects of PEA in an in vivo model of $A D$. The present study also incorporates pharmacological experiments to test the hypothesis that PPAR- $\alpha$ was involved in the effects induced by PEA administration. To this purpose, we co-administered PEA with the GW6471 (N-((2S)-2-(((1Z)-1methyl-3-oxo-3-(4-(trifluoromethyl)phenyl)prop-1-enyl)amino)-3(4-(2-(5-methyl-2-phenyl-1,3-oxazol-4-yl)ethoxy)phenyl)propyl) propanamide), an antagonist of PPAR- $\alpha$ receptor. These experiments are much needed because PEA is currently clinically used for a condition other than AD. Moreover, its safety and tolerability in humans further demonstrate the translational value of this work.

\section{Results}

PEA counteracts $\mathbf{A} \boldsymbol{\beta}$-induced reactive gliosis. Gliosis is a common pathological process after brain injury and neurodegenerative disorders such as $A D .^{26,27}$ On the basis of these evidences, we decided to investigate the possible modifications induced by the intrahippocampal inoculation of A $\beta$ 1-42 and the potential beneficial effect of systemic administration of PEA. First of all, we studied the transcription and expression of the GFAP protein, which is considered one of the most important markers of astrocyte activation. Indeed, GFAP plays a role in mediating most of the signals involved in morphology and functional alterations observed during astrocyte activation. ${ }^{28}$ Immunofluorescence analysis of the hippocampal CA3 area ipsilateral to the injection site revealed that the levels of GFAP were significantly different between the vehicle-inoculated and $\mathrm{A} \beta$-inoculated rats (Figures $1 \mathrm{a}$ and $\mathrm{b}$ ). In fact, we observed an evident increase in the GFAP intensity, and astrocytes show stellate shape and multiple branched processes, which are typical of activated astrocytes (Figure 1b). Such effect was counteracted by systemic treatment with PEA. Indeed, GFAP immunopositivity was decreased in PEA-treated animals, and the shape of astrocytes resembles the one seen in control animals (Figure 1c). Further, the co-administration of PEA with GW6471, a selective PPAR- $\alpha$ antagonist, completely abolished PEA-induced effect (Figures 1d and f).

In line with this observation, results from RT-PCR and western blot experiments, performed in homogenates of hippocampi ipsilateral to the injection site, revealed that both transcription $(P<0.05)$ and expression $(P<0.05)$ of GFAP were significantly higher in $A \beta$-injected rats than in vehicleinjected rats (Figures $1 \mathrm{~g}-\mathrm{j}$ ). Moreover, PEA significantly reduced the $\mathrm{A} \beta$-induced GFAP induction in a PPAR- $\alpha$ dependent manner (Figures 1g-j).

Another mediator crucially involved in the reactive gliosis is the protein S100B. In physiological conditions, S100B behaves as a neurotrophin, promoting the growth of neuritis, stimulating astrocyte proliferation, and increasing free calcium concentrations in both neurons and astrocytes. On the contrary, in case of brain damage, large amounts of S100B are being passively released mainly from astrocytes to diffuse into CSF and blood brain, participating in the amplification of the inflammatory response by further activating microglia and astrocytes. ${ }^{29,30}$ Experiments revealed increased concentrations of $\mathrm{S} 100 \mathrm{~B}$ mRNA and protein, as well as increased densities of S100B-positive astrocytes, in $\mathrm{A} \beta$-injected rats in comparison to the vehicle-injected rats (Figure 2). In particular, immunofluorescence analysis of the CA3 area of the hippocampi ipsilateral to the injection site revealed higher levels of S100B after A $\beta 1-42$ insult; PEA was able to prevent such increase through its interaction with PPAR- $\alpha$ (Figures 2a-f). RT-PCR, western blot, and ELISA experiments were performed to investigate $\mathrm{S} 100 \mathrm{~B}$ mRNA, protein expression, and release in hippocampal homogenates. Results indicated an upregulation of both transcription $(P<0.01)$ and expression $(P<0.01)$, as well as an increased release $(P<0.01)$ of $\mathrm{S} 100 \mathrm{~B}$ in $\mathrm{A} \beta$-injected versus vehicle-injected rats. In these conditions, we observed that PEA controlled the $A \beta$-induced elevation of S100B content in a PPAR- $\alpha$-dependent manner. In fact, GW6471, the selective antagonist for this receptor, completely abolished the effects of PEA (Figures $2 \mathrm{~g}-\mathrm{k}$ ).

As mentioned before, a protracted glial activation is accompanied with the release of several pro-inflammatory mediators that can establish a self-sustaining detrimental cycle that leads to neuronal death, and thus to cognitive dysfunctions. ${ }^{31}$ Among these molecules, IL-1 $\beta$ has been particularly linked to the pathophysiology of $A D$, as IL-1 $\beta$ is involved in neurodegeneration. ${ }^{32,33} \mathrm{~A} \beta$ stimulates IL-1 $\beta$ production which leads to a further increase in glial activation and still more expression of IL-1 $\beta$. IL- $1 \beta$ is able to increase neuronal tau expression and tau hyperphosphorylation, ${ }^{34}$ to

Figure 1 PEA effect on A $\beta$-induced GFAP protein transcription and expression. (a-e) Representative fluorescent photomicrographs $(\times 20$ magnification) of GFAP immunostaining (red) in the CA3 region of hippocampi ipsilateral to vehicle or A $\beta$ 1-42 injection obtained from rats i.p. treated with vehicle, PEA (10 mg/kg), GW6471 $(2 \mathrm{mg} / \mathrm{kg})$, or both drugs. Nuclei were stained with DAPI (blue). (f) Data obtained by the semiquantitative analysis of the OD of GFAP immunostaining. Data are expressed in arbitrary units as means \pm S.E.M. ( $\left.{ }^{* *} P<0.01\right)$. (g) Results of GFAP RT-PCR amplification and (h) densitometric analysis of corresponding bands. Data were generated normalizing to GAPDH ( $\left.{ }^{*} P<0.05\right)$. (i) Representative western blots for GFAP protein from hippocampi ipsilateral to the injection site. (j) Densitometric analyses normalized to $\beta$-actin loading controls $\left({ }^{*} P<0.05\right)$. Statistical analysis was performed by one-way (f) or two-way ( $h$ and $\left.\mathbf{j}\right)$ ANOVA followed by Bonferroni multiple comparison test. Results presented as means \pm S.E.M. of five experiments 
upregulate the complex cdk5/p35, which plays a pivotal role in CNS development, and to induce inducible nitric oxide synthase (iNOS) with concomitant production of nitric oxide (NO). ${ }^{35}$
AD chronic neuroinflammation also shows the upregulation of TNF- $\alpha$ expression ${ }^{36,37}$ mainly involved in the induction of inflammatory tissue damage and neuronal death. ${ }^{35}$
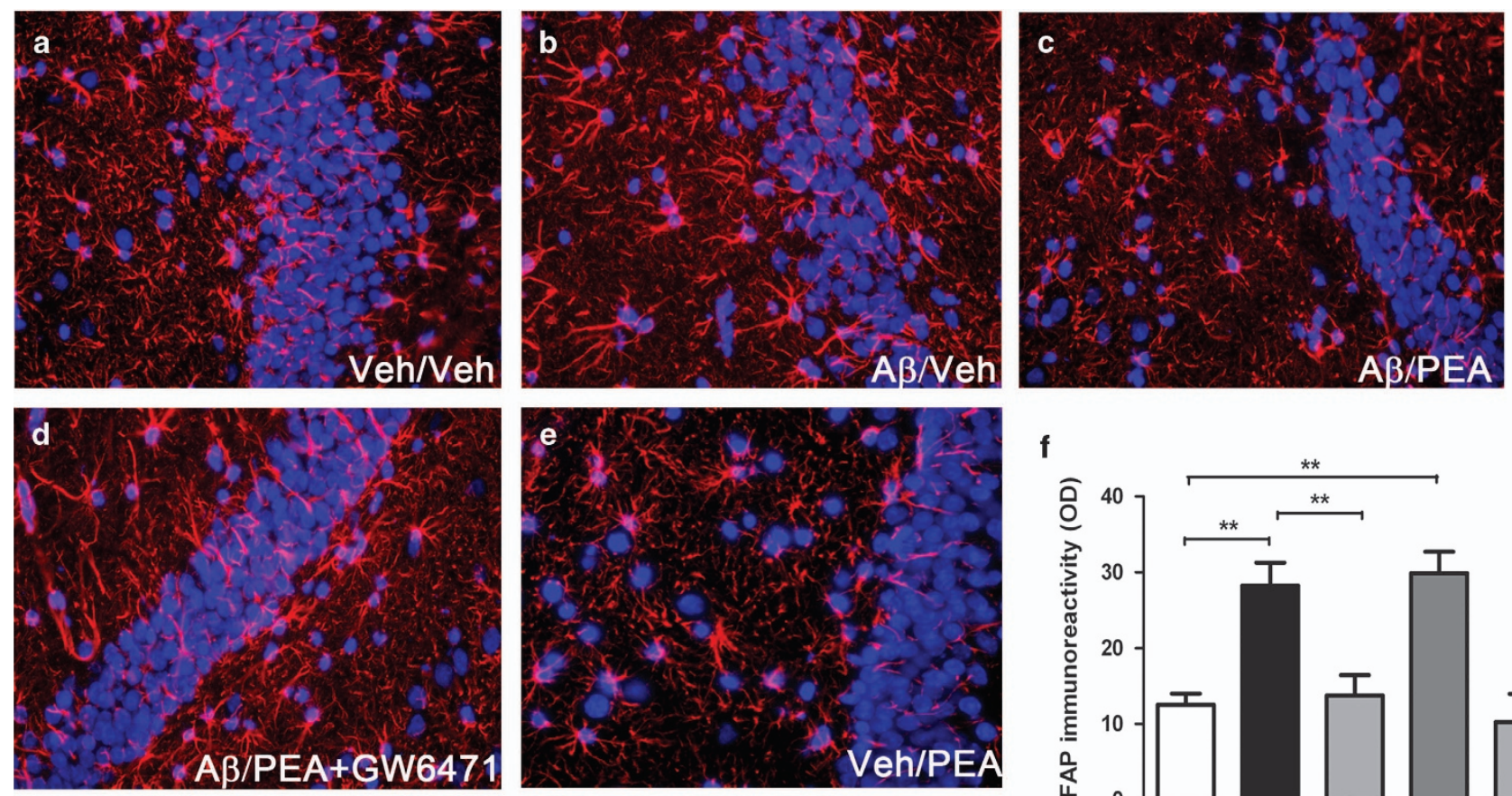

g
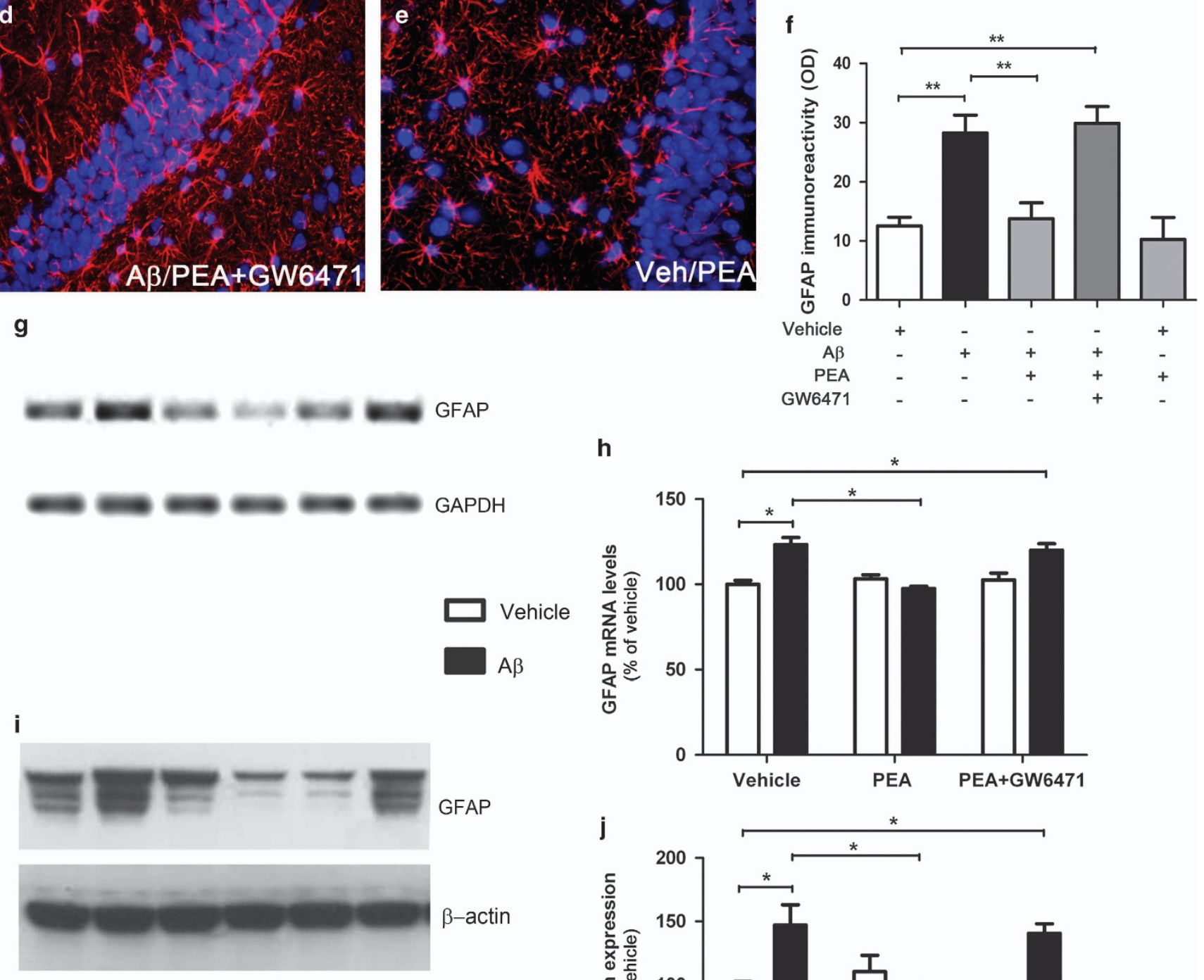

i

h
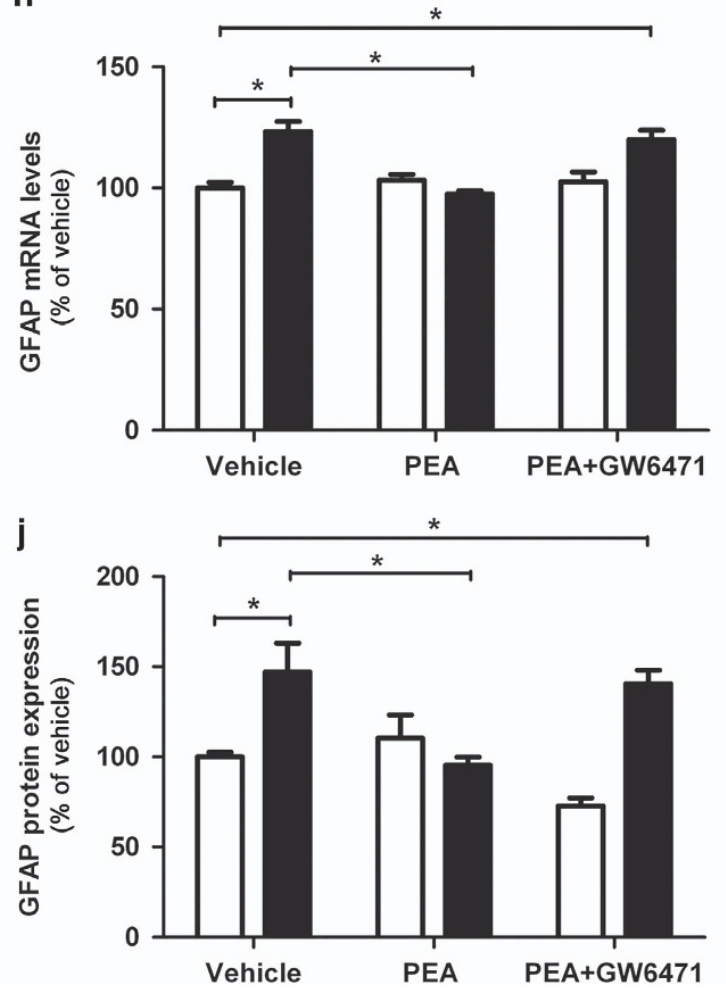
This neuroinflammatory stimulation is further characterized by activation of the complement cascade and induction of the prostanoid-generating enzyme cyclooxygenase-2 (COX-2), ${ }^{38}$ elevated in many neuropathological conditions. ${ }^{39}$ This inducible enzyme causes neurodegeneration in several ways, including the generation of free radicals. ${ }^{40}$
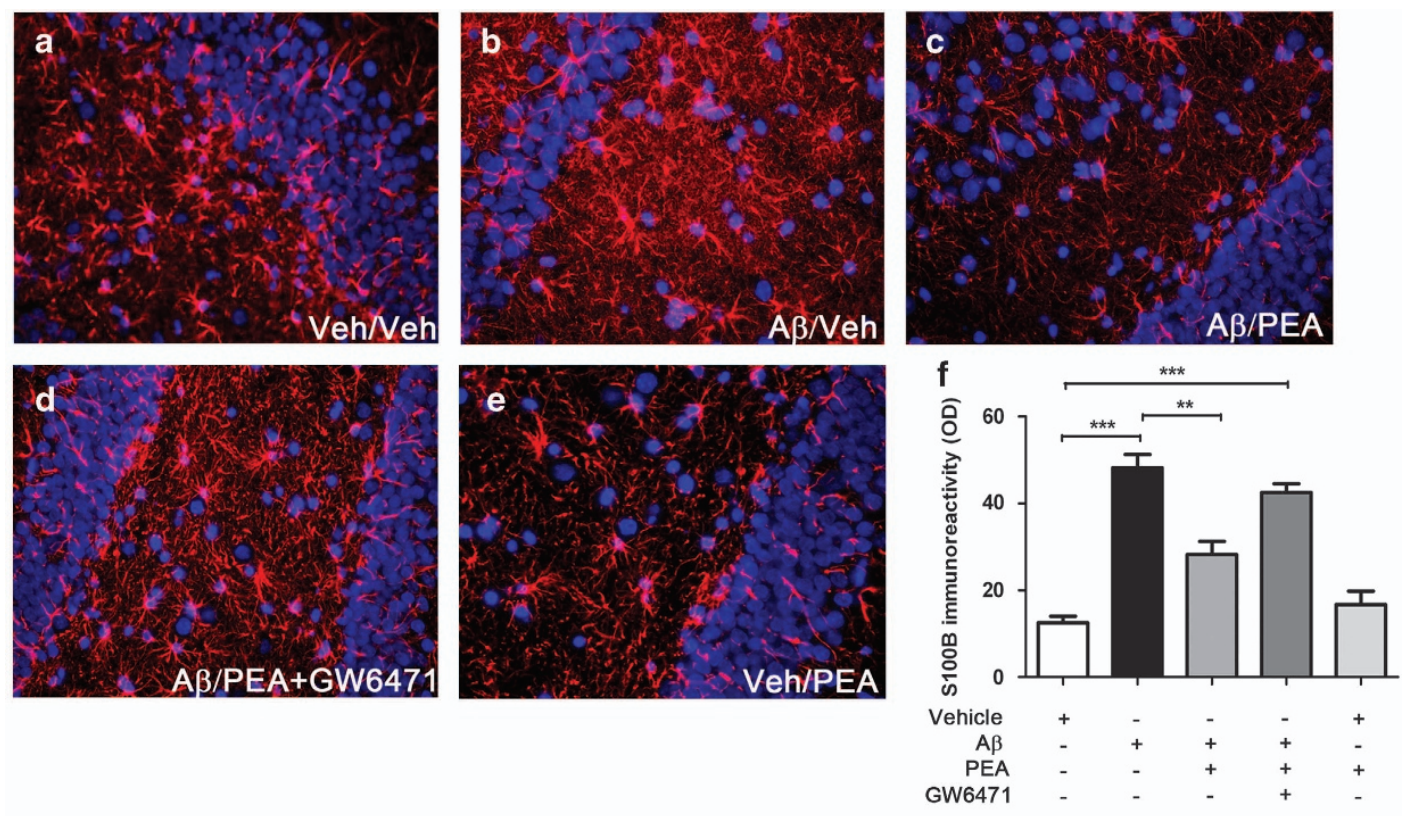

g

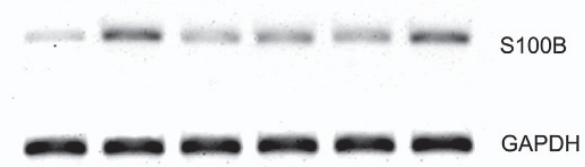

i

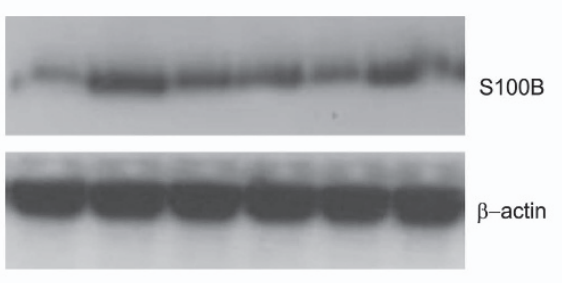

k

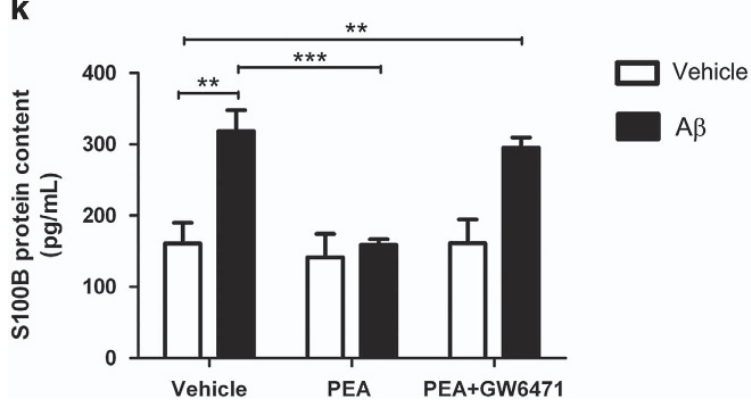

h

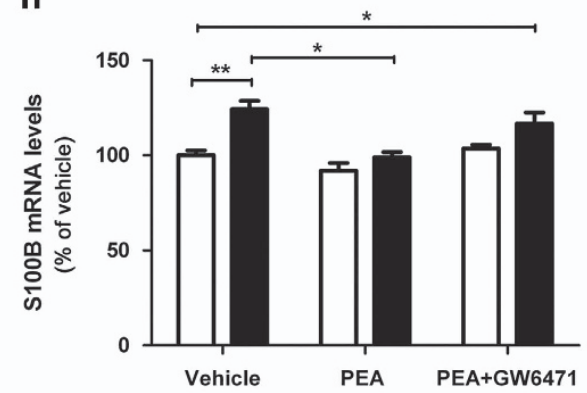

j

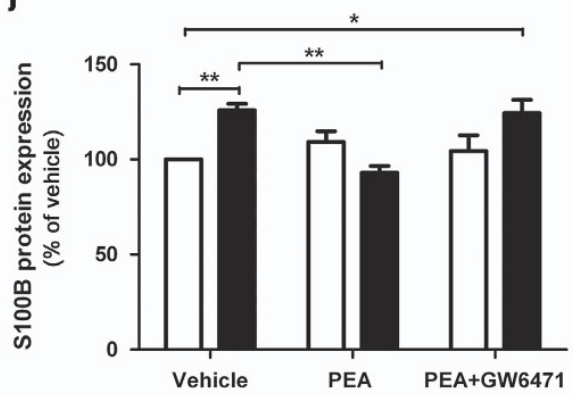


Our results demonstrated that $\mathrm{A} \beta$ 1-42 injection induced the upregulation of iNOS $(P<0.01)$ and COX-2 $(P<0.01)$ in comparison with vehicle-injected rats. PEA blunted $\mathrm{A} \beta$ 1-42 effect $(P<0.01)$ and the administration of GW6471 revealed that PPAR $\alpha$ is partially involved in mediating PEA action $(P<0.05)$ (Figures $3 a-c)$.

Similar findings were obtained when ELISA experiments were performed to quantify the release of IL-1 $\beta$ and TNF $\alpha$ in homogenates of hippocampi ipsilateral to the injection site. We found a marked release of both these pro-inflammatory cytokines, and PEA, once again, was able to control their release. The administration of the selective PPAR- $\alpha$ antagonist, GW6471, completely abolished PEA effects, indicating the significant involvement of such a receptor (Figures $3 \mathrm{~d}$ and $\mathrm{e}$ ). These data clearly show that $\mathrm{A} \beta$ peptide causes a marked activation of glial cells, starting the so-called reactive gliosis process, which is efficaciously counteracted by PEA treatment. In addition, these data confirmed a clear involvement of PPAR- $\alpha$ receptor in mediating the effect of PEA.

PEA effects on amyloidogenic pathway. $\beta$-secretase (BACE1) is a type I transmembrane aspartyl protease. It is predominantly expressed in neuronal cells, and localizes to acidic compartments in the secretory pathway where the production of $\mathrm{A} \beta$ occurs. Indeed, $\mathrm{A} \beta$ generation is abolished in BACE1 knockout mice, ${ }^{41}$ whereas $\mathrm{A} \beta$ formation is increased by the overexpression of BACE1. ${ }^{42}$ Cleavage of APP by BACE 1 is the first step in a process essential for $A \beta$ generation, and several studies demonstrated how BACE1 expression is able to control the dynamics of $\beta$-secretase activity in processing APP to generate $\mathrm{A} \beta .^{43}$ Moreover, in vitro studies demonstrated that the $A D$-associated Swedish mutant APP is associated with increased BACE1 activity developing the phenotypes typical of axonal transport defects because of an enhanced cleavage of APP. ${ }^{44}$ Indeed, the regulation of APP transcription might play an important role in $A D$ susceptibility. Several studies identified higher levels of APP mRNA in AD brains, ${ }^{45}$ and highlighted that increased expression of APP correlates with $\mathrm{A} \beta$ deposition in brain with severe head injury. ${ }^{46}$ Given the importance of these proteins in $A D$ pathogenesis and progression, western blot analysis for BACE1 and APP was performed. Our results showed a significant BACE1 and APP protein expression increase $(P<0.05$ and $P<0.01$, respectively) in $\mathrm{A} \beta$-injected rat compared with controls (Figure $4 a$ ), as confirmed by relative densitometric analysis (Figures $4 \mathrm{~b}$ and $\mathrm{c}$ ). This expression is statistically attenuated by PEA treatment $(P<0.05$ and $P<0.01$, respectively, for BACE1 and APP expression), when compared with the vehicle-treated group. The selective PPAR- $\alpha$ antagonist, GW6471, abolished PEA effects.
PEA rescues Wnt pathway thus modulating tau protein phosphorylation. The irregular phosphorylation of the microtubule-associated protein tau is a prominent aspect of AD. It is now established that glycogen synthase kinase $3 \beta$ $(\mathrm{GSK} 3 \beta)$ is involved in normal and pathological tau phosphorylation. Indeed, activation of the canonical Wnt pathway leads to two main molecular mechanisms represented by the inhibition of GSK3 $\beta$ and the relative accumulation/degradation of $\beta$-catenin in the cytoplasm. ${ }^{47}$ The latter signaling pathway has been found to be dysregulated in the $A D$ brain. ${ }^{48}$ We have already demonstrated that $\mathrm{S100B}$ is able to induce the expression of Dickopff-1 (Dkk-1), causing tau protein hyperphosphorylation. ${ }^{49}$ In addition, recent data demonstrated the increased expression of Dkk-1 in brains of $A D$ patients suggesting that dysfunction of the Wnt signaling could contribute to AD pathology. ${ }^{50}$

Utilizing western blot analysis, we evaluated the expression of the main proteins involved in the canonical Wnt pathway. Results of immunoblot experiments and their relative densitometric analysis are illustrated in Figure 5. A $\beta$-injected rats showed increased concentrations of Dkk-1 in comparison with vehicle-injected rats $(P<0.05)$. Under these conditions, PEA was able to control Dkk- 1 expression in a PPAR- $\alpha$-dependent manner (Figure $5 b$ ). This set of experiments also revealed a marked alteration in the levels of the Wnt pathway proteins. In fact, we found a significant increase in GSK3 $\beta$ expression in $\mathrm{A} \beta$-injected rats in comparison with vehicle-injected rats $(P<0.001)$. Such effect was totally abolished by the pharmacological treatment with PEA $(P<0.001)$ through a mechanism which partially involves PPAR- $\alpha$ (Figure $5 \mathrm{c}$ ). In parallel, we observed a marked decrease of $\beta$-catenin protein in the hippocampus of $\mathrm{A} \beta$-injected rats in comparison with vehicleinjected rats $(P<0.01)$. Physiological levels of $\beta$-catenin were founded in $A \beta$-injected rats systemically treated with PEA $(P<0.05)$ demonstrating, once again, the ability of this compound to counteract the damage induced by peptide inoculation. Co-administration of PEA with GW6471 attenuated such effect, demonstrating that PEA interacts with PPAR- $\alpha$ to achieve the observed effects (Figure $5 d$ ). Growing evidence indicates that disrupted Wnt signaling may be a direct link between $\mathrm{A} \beta$ toxicity and tau hyperphosphorylation, ultimately leading to neuronal degeneration. For this reason, we performed western blot experiments using a specific primary antibody able to bind tau protein on the phosphoSer396, which is recognized to be the phosphorylation site mainly related to neurofibrillary pathology in AD brain. ${ }^{51}$ The expression of phosphorylated tau ( $p$-tau) was normalized for total tau content using a polyclonal primary antibody. Results highlighted a significant increase in the $\mathrm{p}$-tau/tau ratio after $\mathrm{A} \beta$ $1-42$ injection $(P<0.01)$, normalized by PEA $(P<0.05)$ in a manner partially dependent on its PPAR- $\alpha$ interaction

Figure 2 Effect of PEA on $\mathrm{A} \beta$-induced $\mathrm{S} 100 \mathrm{~B}$ protein transcription, expression, and release. (a-e) Representative fluorescent photomicrographs ( $\times 20$ magnification) of $\mathrm{S} 100 \mathrm{~B}$ immunostaining (red) in the CA3 region of hippocampi ipsilateral to vehicle- or $\mathrm{A} \beta 1-42$ injection site obtained from rats i.p. treated with vehicle, PEA (10 mg/kg), GW6471 (2 mg/kg), or both drugs. Nuclei were stained with DAPI (blue). (f) Data obtained by the semiquantitative analysis of OD of S100B immunostaining. Data are expressed in arbitrary units as means \pm S.E.M. $\left.{ }^{* * *} P<0.001 ;{ }^{* *} P<0.01\right)$. (g) Results of S100B RT-PCR amplification and (h) densitometric analysis of corresponding bands. Data were generated normalizing to GAPDH ( ${ }^{\star *} P<0.01$; $\left.{ }^{*} P<0.05\right)$. (i) Representative western blots for S100B protein from hippocampi ipsilateral to the injection site. (j) Densitometric analyses normalized to $\beta$-actin loading controls $\left({ }^{* *} P<0.01 ;{ }^{*} P<0.05\right)$. (k) Measurement of S100B release by ELISA in homogenate hippocampi ipsilateral to theA $\beta$ injection site $\left({ }^{\star \star *} P<0.001 ;{ }^{* *} P<0.01\right)$. Statistical analysis was performed by one-way (f) or two-way (h, j, and $\left.\mathbf{k}\right)$ ANOVA followed by Bonferroni multiple comparison test. Results presented as means \pm S.E.M. of five experiments 

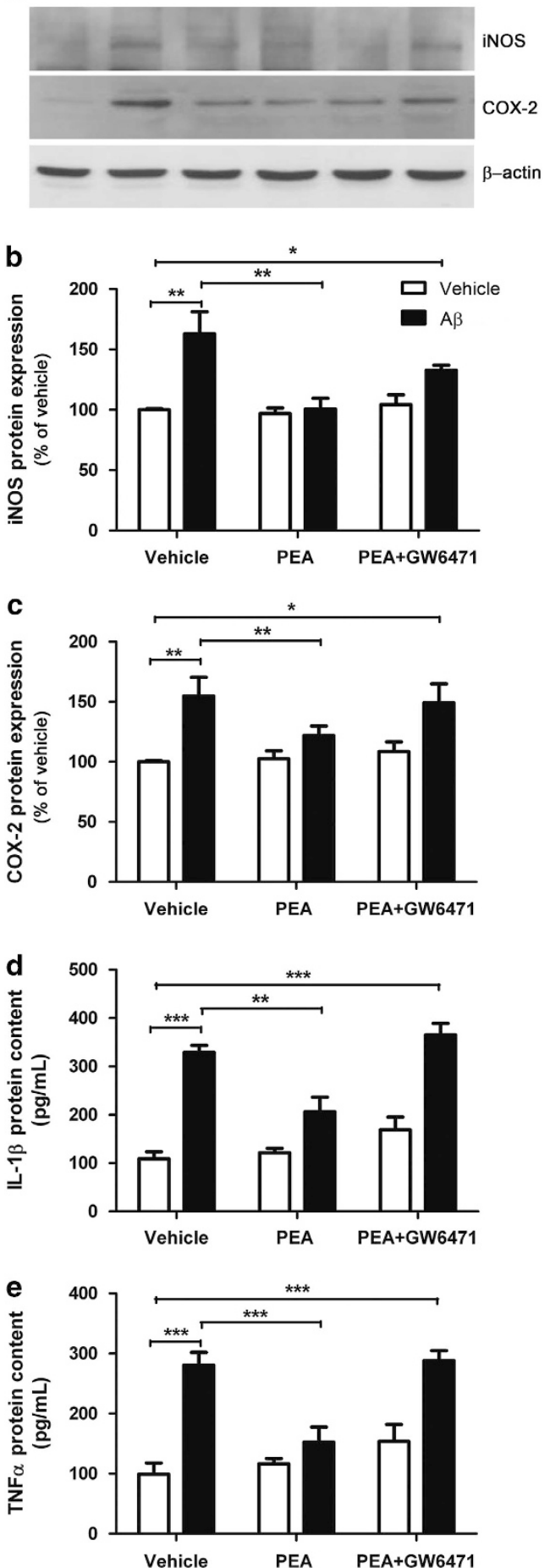

Figure 3 Effect of PEA on expression and release of inflammatory mediators induced by $\mathrm{A} \beta$ injection. (a) Representative western blots for INOS and COX-2 proteins from hippocampi ipsilateral to the injection site and ( $b$ and $\mathbf{c}$ ) relative densitometric analyses normalized to $\beta$-actin loading controls $\left({ }^{* *} P<0.01\right.$; ${ }^{\star} P<0.05$ ). Measurement of IL-1 $\beta$ (d) and TNF $\alpha$ (e) release by ELISA in homogenate hippocampi ipsilateral to the $A \beta$ injection site $\left({ }^{\star \star *} P<0.001\right.$; $\left.{ }^{\star \star} P<0.01\right)$. Statistical analysis was performed by two-way ANOVA followed by Bonferroni multiple comparison test. Results presented as means \pm S.E.M. of five experiments a

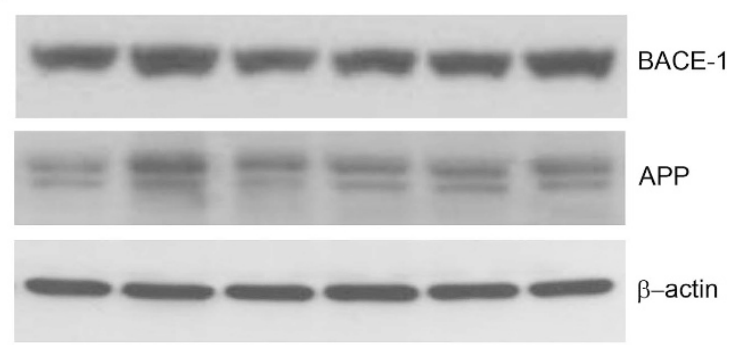

b

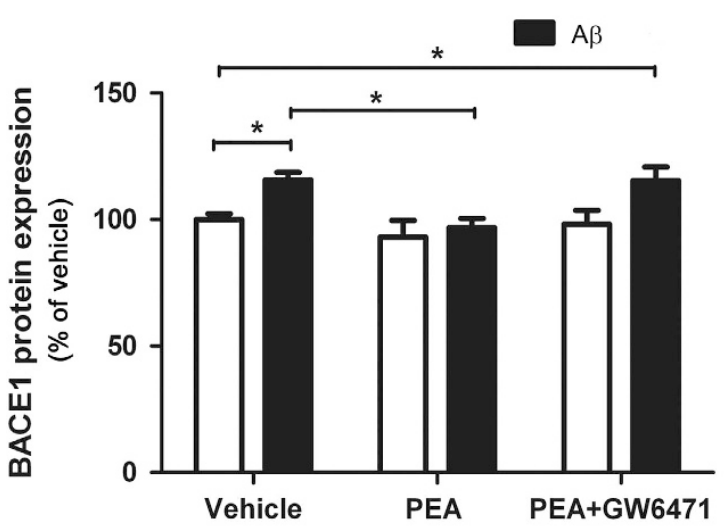

C

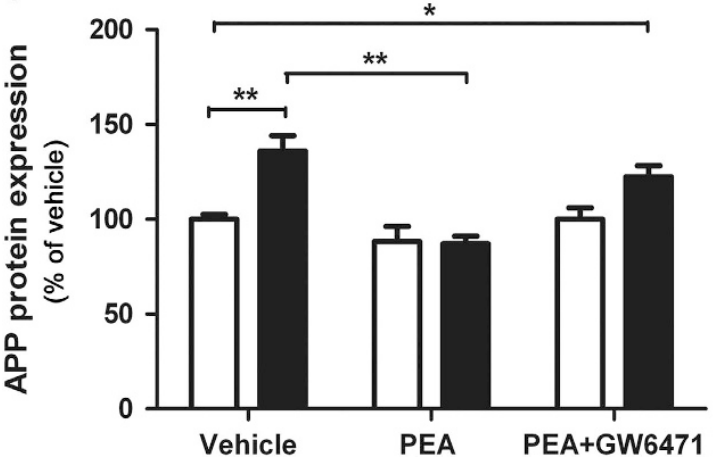

Figure 4 Effect of PEA on amyloidogenic pathway. (a) Representative western blots for BACE 1 and APP proteins from hippocampi ipsilateral to the injection site and ( $\mathbf{b}$ and $\mathbf{c}$ ) relative densitometric analyses normalized to $\beta$-actin loading controls $\left({ }^{*} P<0.01 ;{ }^{*} P<0.05\right)$. Statistical analysis was performed by two-way ANOVA followed by Bonferroni multiple comparison test. Results presented as means \pm S.E.M. of five experiments

(Figure 5e). Collectively, these data support a pivotal role of PEA in modulating the $\mathrm{A} \beta$-induced alterations in the Wnt pathway and normalizing the physiological level of phosphorylated tau protein.

PEA effects on neuronal integrity. To investigate the effects of $\mathrm{A} \beta$ 1-42 injection on neuronal survival, we measured the expression of the microtubule-associated protein 2 (MAP-2) by immunofluorescence analysis. MAP-2 is one of the main cytoskeletal proteins in neurons; in mammalian nervous system, MAP-2 regulates microtubule dynamics, and it plays an important role in neurite outgrowth and dendrite development. ${ }^{52}$ Morphologically, the reduction in neurite outgrowth is observed in neural cells from $A D$ 
patients. Indeed, recent studies demonstrated that MAP-2 expression pattern was significantly reduced compared with the control group, highlighting that mature neurons are

a

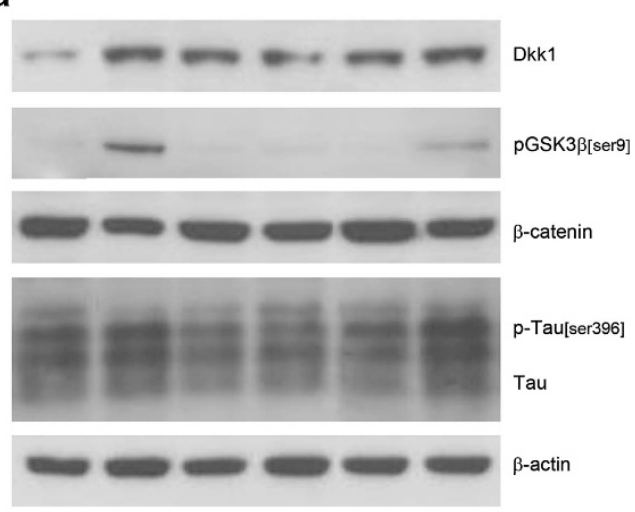

b
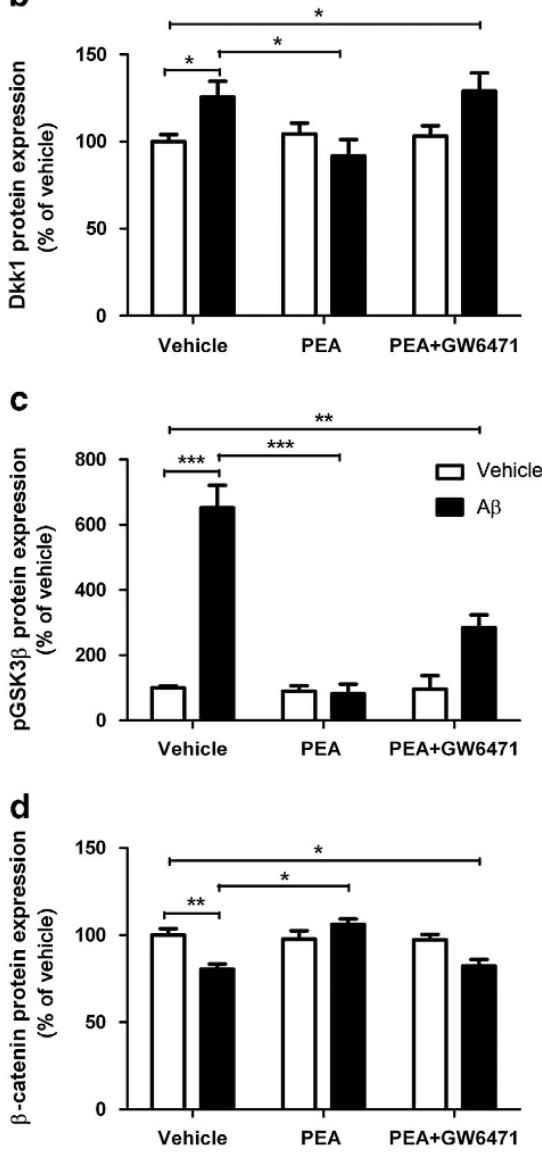

e

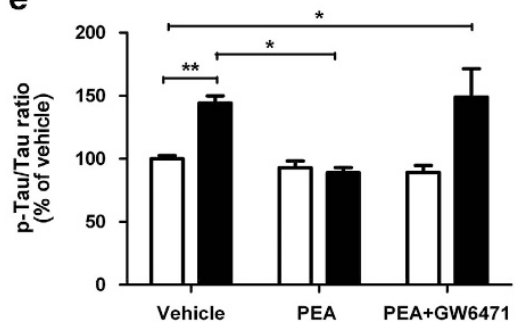

significantly decreased in the patients' group. ${ }^{53}$ In our study, results from MAP-2-stained hippocampi indicated that $A \beta$ 1-42 injection caused a severe depletion of neurons, especially in the dentate gyrus, compared with vehicleinjected rats $(P<0.05)$. By means of MAP-2 staining and relative quantification of immunopositive cells, we observed that PEA treatment significantly reduced $\mathrm{A} \beta$-provoked neuronal loss $(P<0.05)$ through its interaction with PPAR- $\alpha$ $(P<0.05)$ (Figures 6a-f). Moreover, our results indicate that PEA was able to exert an important neuroprotective effect through PPAR- $\alpha$ involvement.

PEA rescues the $A \beta$-induced deficits in the reversal learning phase of the Morris water maze. To examine whether systemic treatment with PEA can result in recovery from memory deficit induced by hippocampal A $\beta$ 1-42 infusion, the Morris water maze (MWM) task was carried out 3 weeks after surgery, as illustrated in the flow chart (Figure 7a). Rat weight was monitored every day until the beginning of behavioral tests. No alterations were observed (data not shown).

All groups were trained for three consecutive days on spatial training procedure of four trials session per day. During these sessions, rats had to learn to localize a hidden platform set always in a fixed place. All rats, regardless of any treatment, were equally able to acquire the cognitive task. Indeed, ANOVA for repeated measures (with trials as repeated measures) revealed a trial effect $(F(11,418)=35.031 ; P<0.0001)$ but did not reveal significant differences among groups in the acquisition performances $(\mathrm{F}(11,418)=1.026 ; P=0.422)$ (Figure $7 \mathrm{~b})$.

The effect of $\mathrm{A} \beta$ 1-42 inoculation on long-term memory was analyzed $24 \mathrm{~h}$ after the last acquisition day on a single 60-s probe trial. During the probe test, the platform was removed from the water maze tank and the time spent in the target quadrant where the platform was previously located was measured as a parameter of long-term memory retention. ANOVA test revealed significant differences neither for the central treatment $(\mathrm{F}(1,38)=0.506 ; P=0.481)$ nor for the peripheral treatment $(\mathrm{F}(1,38)=0.464 ; P=0.499)$ nor for the interaction between central and peripheral treatments $(\mathrm{F}(1,38)=0.623 ; P=0.435)$ showing that $\mathrm{A} \beta 1-42$ did not alter long-term memory functions (Figure 7c).

On day 5 , rats were tested for reversal learning capabilities during a unique session of five trials. The hidden platform was relocated into the quadrant on the opposite side where the platform was previously positioned, thus rats had to quickly understand the new experimental setting, and consequently to remodel their escape strategy. Figure $7 d$ shows the effect of PEA administration on reversal learning performances during

Figure 5 Effects of PEA on the Wnt pathway and tau protein phosphorylation. (a) Representative western blots from hippocampal proteins probed with the indicated antibodies. (b-e) Relative densitometric analyses. Data were generated normalizing proteins of interest to $\beta$-actin loading controls $\left({ }^{\star \star \star} P<0.001 ;{ }^{* \star} P<0.01\right.$; $\left.{ }^{\star} P<0.05\right)$. Statistical analysis was performed by two-way ANOVA followed by Bonferroni multiple comparison test. Results presented as means \pm S.E.M. of five experiments 
the first trial. ANOVA revealed a statistically significant interaction among treatments $(\mathrm{F}(1,38)=10.278 ; P=0.003)$. Post hoc comparisons revealed a statistically significant

a

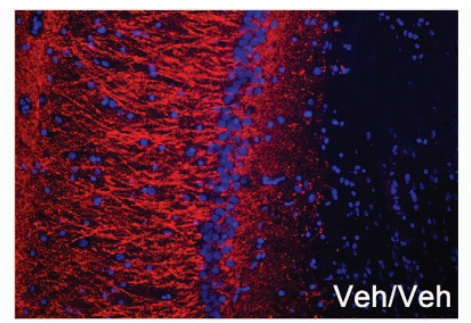

b

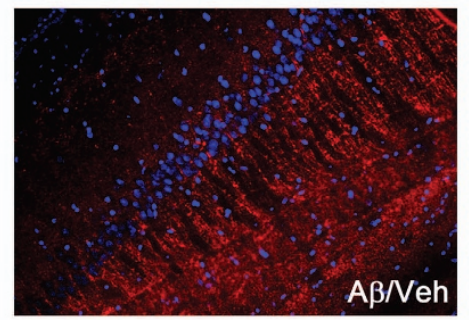

C

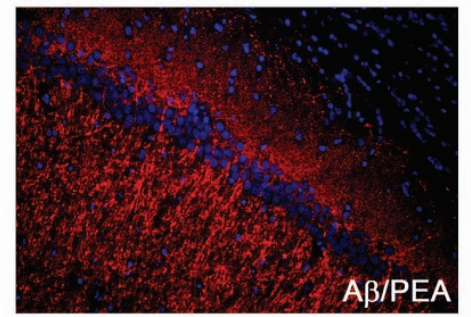

d

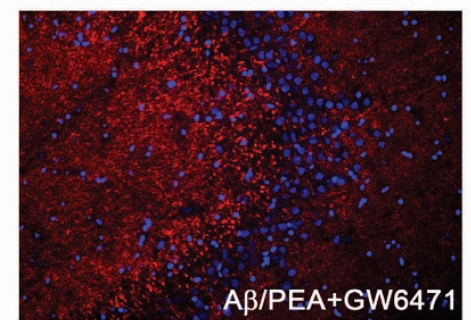

e

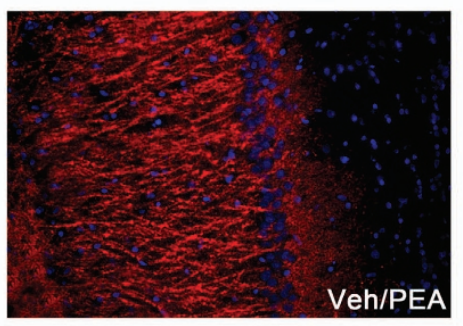

f

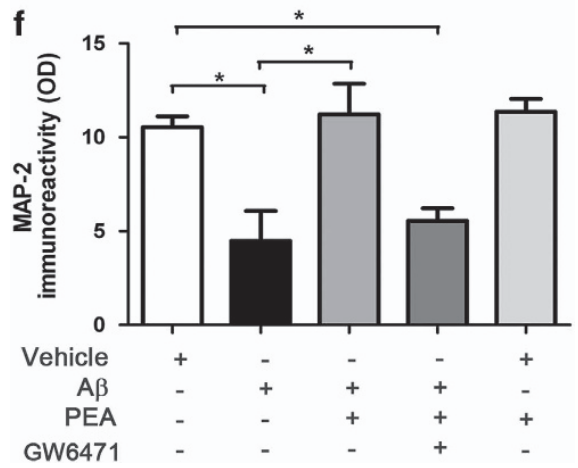

difference between $\mathrm{A} \beta /$ Veh versus Veh/Veh, and $\mathrm{A} \beta / \mathrm{Veh}$ versus $\mathrm{A} \beta / \mathrm{PEA}$ animals $(P<0.05)$, thus showing that $\mathrm{A} \beta$ injected rats were impaired in the fast adjustment to a change in the platform location compared with the vehicle-injected animals. Interestingly, we found that PEA administration statistically prevented the memory-impairing effect induced by $\mathrm{A} \beta \quad(P<0.05) \quad$ (Figure $7 \mathrm{~d})$. No statistically significant differences were found among groups in the escape latency during trials $2-5(\mathrm{~F}(3,114=1.36 ; P=0.26)$.

\section{Discussion}

The current results clearly demonstrate, for the first time in a rat model of $A D$, the ability of PEA to attenuate neuropathology by modulating neuroinflammation. This supports the view that astrocyte-unregulated activation can be considered an appropriate and promising therapeutic target for AD treatment. Furthermore, we demonstrated in vivo that PPAR- $\alpha$ is involved in mediating PEA beneficial effects. Such findings are new and of great interest because AD represents one of the major health concern, with a pressing need to develop new agents able to prevent or treat this disorder. Currently, an unresolved goal of preclinical investigation is to recognize tools capable to selectively regulate pro-inflammatory overactivation of neuroglia, restoring its physiological properties. The capacity of PEA to modulate the protective responses during inflammation suggests that endogenous PEA may be part of the complex homeostatic apparatus controlling the basal threshold of inflammatory processes. For this reason, we aimed to study the effects of PEA in a rat model of AD and here, we provide the first in vivo evidence that PEA exerts simultaneously anti-inflammatory and neuroprotective effects. It is commonly accepted that $\mathrm{A} \beta$ deposits can be associated with local cell loss, oxidative stress, and neuroglial activation. Glia possess endogenous homeostatic mechanisms/molecules that can be seriously affected as a result of tissue damage. As a consequence, activated glial cells lose their physiological functions and acquire a reactive phenotype, characterized by profound morphological and functional alterations. ${ }^{28}$ Among these, GFAP and S100B overexpression is the best-known hallmark of activated astrocytes. ${ }^{54,55}$ In our model, we detected marked alteration of both these proteins. In fact, our results show that hippocampal astrocytes had significantly larger GFAP surface and express higher immunopositivity for S100B. Interestingly, PEA negatively modulated both GFAP and S100B transcription and expression, through its interaction with PPAR- $\alpha$ receptor.

In this study, we highlighted the existence of an inflammatory state induced by $\mathrm{A} \beta$ 1-42 infusion, as detected by the

Figure 6 PEA effect on neuronal integrity. (a-e) Representative fluorescent photomicrographs ( $\times 20$ magnification) of MAP-2 immunostaining (red) in the CA3 region of hippocampi ipsilateral to vehicle or $A \beta 1-42$ injection site obtained from rats i.p. treated with vehicle, PEA (10 mg/kg), GW6471 (2 mg/kg), or both drugs. Nuclei were stained with DAPI (blue). (f) Data obtained by the semiquantitative analysis of the optical density (OD) of MAP-2 immunostaining. Data are expressed in arbitrary units as means \pm S.E.M. of five experiments $\left({ }^{*} P<0.01\right)$. Statistical analysis was performed by one-way ANOVA followed by Bonferroni multiple comparison test 


\section{a}

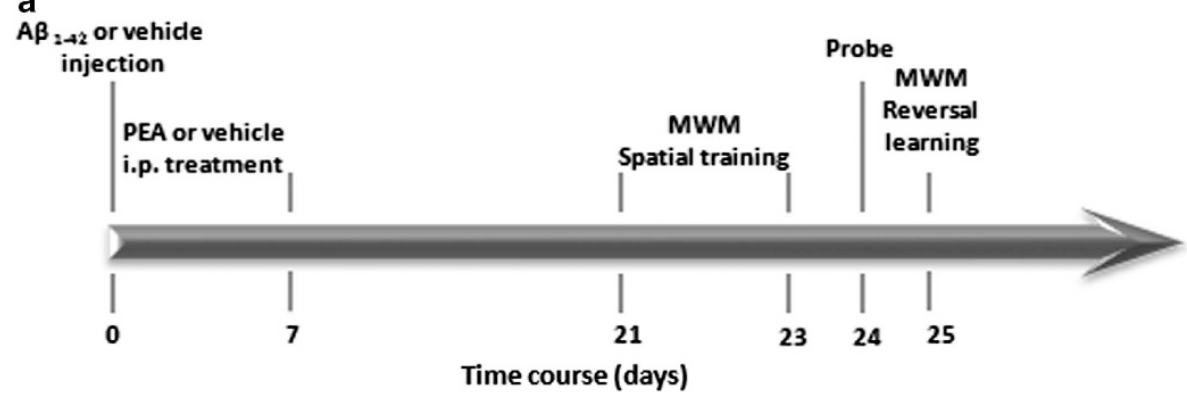

b
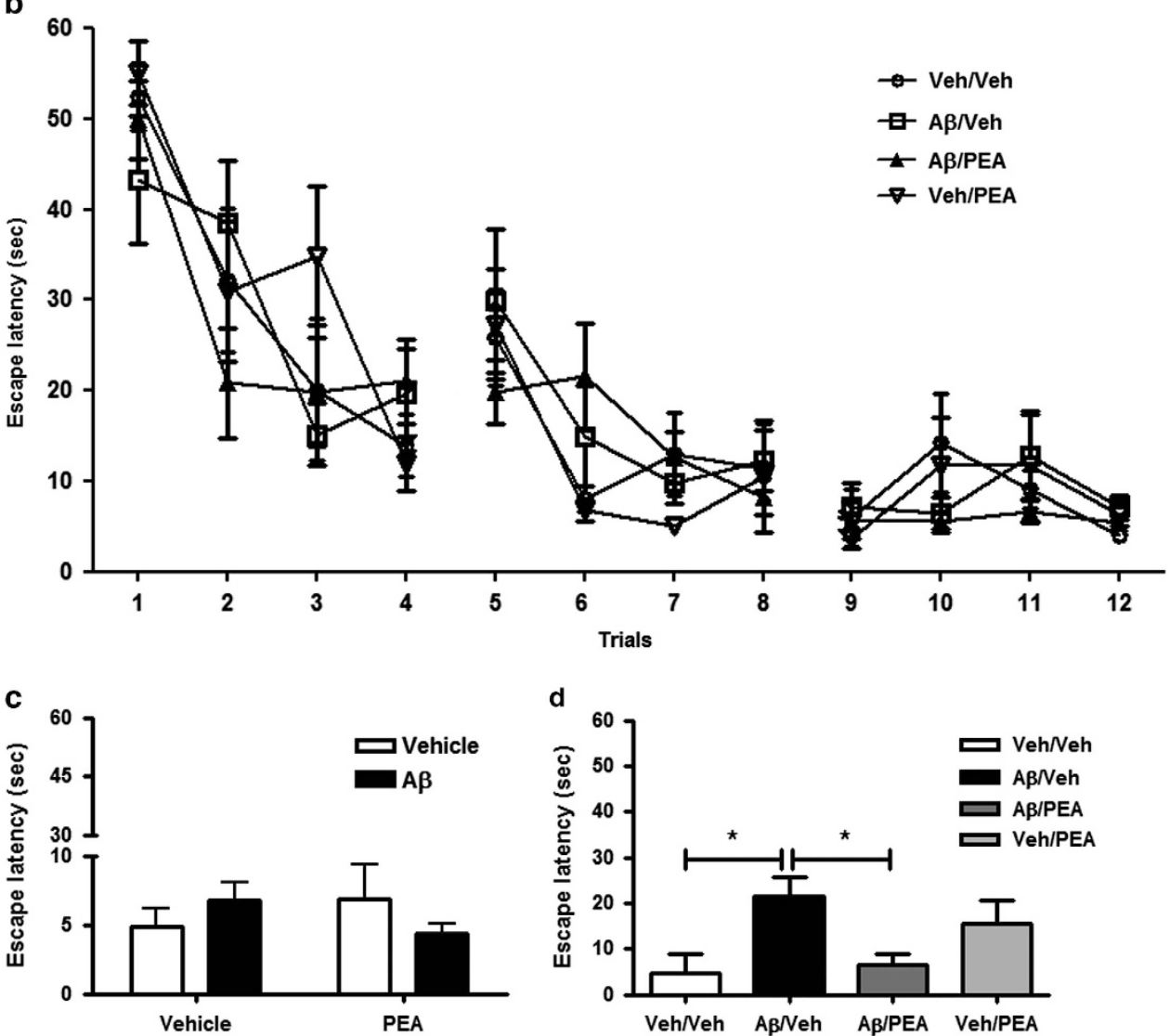

Figure 7 PEA rescues the A $\beta$-induced deficits in the reversal learning phase of the Morris water maze. (a) Diagram of the experimental design. (b) Mean latency (seconds) for finding the escape platform during the spatial training. No significant differences were detected among all groups. (c) Mean latency (seconds) to reach the quadrant where the platform was located during the acquisition. No significant differences were detected among all groups. (d) Mean latency (seconds) for finding the escape platform during the reversal learning. $A \beta /$ Veh rats showed longer escape latency versus Veh/Veh $\left({ }^{*} P<0.05\right)$ and $A \beta / P E A$ rats $\left({ }^{*} P<0.05\right)$. Statistical analysis was performed by two-way ANOVA followed by Bonferroni multiple comparison test. Results presented as means \pm S.E.M

increased expression and release of the some key regulators of inflammatory process. Remarkably, PEA reduced iNOS and COX-2 overexpression and the enhanced release of IL- $1 \beta$ and TNF- $\alpha$. Overall, these findings suggest that PEA exerts a key role in regulating astrogliosis and important functional changes, which contribute to disease progression.

Astrocytic cytokines may prompt the synthesis of acutephase proteins such as APP ${ }^{56}$ increasing the production of $\mathrm{A} \beta$, regulating the cytokine cycle itself, ${ }^{32}$ and inducing neuronal death ${ }^{34}$ responsible for the neurodegenerative consequences. Astrocytes could be induced by pro-inflammatory stimuli to promote the expression of BACE1, thus increasing the conversion of APP into the neurotoxic insoluble $\mathrm{A} \beta$ which could, in turn, induce astrocytes to produce more inflammation-like glial responses. ${ }^{35,57}$ Here, we demonstrate the ability of PEA to reduce the expression of BACE1 and APP, proteins directly involved in the amyloidogenic pathway. Collectively, these results identify PEA as a potential agent that is able to stop the detrimental cycle in which neuroinflammation and amyloidogenesis cooperate in sustaining the pathological state and the activation process of astrocytes.

Besides $\mathrm{A} \beta$ accumulation in SP, the accumulation of hyperphosphorylated tau proteins that yield to NFT formation 
is another hallmark characteristic in AD brain. Many data indicate that inhibition of the canonical Wnt pathway contributes to the pathophysiology of neurodegenerative disorders. Previous studies ${ }^{58}$ demonstrated the role for Dkk-1 in the mechanisms of $\mathrm{A} \beta$ toxicity. The ability of $\mathrm{A} \beta$ to induce the expression of Dkk-1 causes an increased activity of GSK3 $\beta$ resulting in the hyperphosphorylation of tau protein. Here, we show, for the first time in an in vivo model, the ability of PEA to restore the alteration in the Wnt pathway caused by $\mathrm{A} \beta 1-42$ hippocampal infusion, and to reduce phosphorylated tau protein overexpression. These findings indicate an important neuroprotective function for this endogenous compound and, once again, highlight an important involvement of PPAR- $\alpha$. To deeply investigate the effect of PEA on neuronal circuitry, we decided to perform analysis on a neuronal marker, MAP-2. Our findings showed an important role of PEA in restoring MAP-2 expression that resulted reduced after $\mathrm{A} \beta$ injection, confirming its neuroprotective effect.

Finally, we decided to perform a MWM test to evaluate the effect of PEA on cognitive functioning. We found that $A \beta 1-42-$ infused rats did not present deficits in the acquisition and in the long-term retention of the task. This is of translational value because clinical observations report that general and profound learning dysfunctions do not occur in the early course of AD. Importantly, we found that A $\beta$ 1-42 infusion in the dorsal hippocampus results in reversal learning deficits, which could be partially compared to working-like memory in humans. ${ }^{59,60}$ Impairment of working memory has been found to be a precocious marker for the future development of dementia. ${ }^{61,62}$ Interestingly, PEA was able to restore the A $\beta$ 1-42induced deficits, suggesting its capability to improve reversal learning deficits.

The current investigation provides evidence that PEA, by activating PPAR- $\alpha$, rescues altered molecular pathways as well as behavioral impairments that can mimic some early traits of AD. Considering the extreme safety and tolerability of PEA in humans, our findings offer new opportunity in the already fruitless world of AD treatment.

\section{Materials and Methods \\ Animals. Male adult Sprague-Dawley rats $(250-275 \mathrm{~g}$ at the time of surgery; Charles River Laboratories, Calco, Italy) were individually housed in a temperature- controlled $\left(20 \pm 1^{\circ} \mathrm{C}\right)$ vivarium and maintained under a $12 \mathrm{~h}$ light/dark cycle $(07: 00$ AM lights on - 07:00 PM lights off). Food and water were available ad libitum. All experiments were carried out during the light phase. All procedures were approved by the Italian Ministry of Health (Rome, Italy) and performed in compliance with the guidelines of the European Communities Council (2010/63/UE).}

Surgical procedures. Rats ( $n=9-12$ for each experimental group) were anesthetized intraperitoneally (i.p.) with sodium pentobarbital $(50 \mathrm{mg} / \mathrm{kg}$ ), placed in a stereotaxic frame and unilaterally inoculated with human $A \beta$ 1-42 (Tocris Cookson, Bristol, UK) into the dorsal hippocampus (coordinates relative to the bregma: AP: $-3 \mathrm{~mm}, \mathrm{ML}: \pm 2.2 \mathrm{~mm}$, and DV: $-2.8 \mathrm{~mm}){ }^{63}$ The coordinates and dose of A $\beta$ 1-42 were chosen according to literature and the results of a series of pilot experiments. ${ }^{64}$ The peptide was dissolved in artificial cerebral-spinal liquid (aCSF) to the concentration of $2 \mu \mathrm{g} / \mu \mathrm{l}$. Fibrillar amyloid was formed by incubation at least for $24 \mathrm{~h}$ at $37^{\circ} \mathrm{C}$. ${ }^{65} \mathrm{~A}$ volume of $2.5 \mu \mathrm{l}$ was injected using a microdialysis pump, keeping the flow to the constant value of $0.5 \mu \mathrm{l} / \mathrm{min}$. Injection needles were left in place for additional $60 \mathrm{~s}$ to facilitate the diffusion of solution. Control rats underwent the same procedure and were inoculated with an equivalent volume of aCSF.

Drug treatment. PEA and GW6471 were both from Tocris (Bristol, UK). PEA and GW6471 were dissolved in saline:PEG:Tween-80 in a 90:5:5 ratio (v/v)
(Sigma-Aldrich, Milan, Italy). Control rats were i.p. given an equivalent volume of the proper vehicle. Vehicle, PEA (10 mg/kg), GW6471 $(2 \mathrm{mg} / \mathrm{kg}$ ), or both drugs were i.p. administered once a day for seven consecutive days, starting from the day of the surgery. The doses were chosen according to literature and the results of a series of pilot experiments ${ }^{66,67}$ (data not shown).

\section{Biochemical evaluations}

Tissue collection: Twenty-eight days after surgery, rats were killed by decapitation. For immunoblotting, ELISA, and RT-PCR experiments, hippocampi were isolated and frozen using 2-methylbutane. We focused on the hippocampus, which is one of the brain areas earliest and most severely affected by AD. For morphological analysis, whole brains were frozen in 2-methylbutane and stored at $-80^{\circ} \mathrm{C}$.

Reverse transcriptase-polymerase chain reaction. Total RNA was extracted from homogenized hippocampi ipsilateral to the injection site using the lysis reagent provided in NZY Total RNA isolation kit (NZYTech, Lda., Lisbon, Portugal) according to the manufacturer's protocol. The extracted RNA was subjected to DNase I (NZYTech, Lda) treatment at $25^{\circ} \mathrm{C}$ for $15 \mathrm{~min}$ and eluted in $30 \mu \mathrm{l}$ of RNase-free water. The total RNA concentration was determined by Nanodrop 1000 spectrophotometer (Thermo-scientific, Rockford, IL, USA) and purity of sample was determined according to the $260 / 280 \mathrm{~nm}$ ratio. One microgram of RNA was reversed transcribed into complementary DNA (cDNA) using oligo(dT) and random primers included in the First-strand CDNA synthesis kit (NZYTech, Lda.); then RNA/DNA hybrids were digested with RNase $\mathrm{H}$ from $E$. coli, according to the manufacturer's specifications. All PCR experiments were performed using Supreme NZYTaq DNA polymerase (NZYTech, Lda.) with specific primers for Rattus norvegicus GFAP (forward primer 5'-TGG CCA CCA GTA ACA TGC AA-3'; reverse primer 5'-CTC GAT GTC CAG GGC TAG CT-3'), S100B (forward primer $5^{\prime}$-TCA GGG AGA GAG GGT GAC AA-3'; reverse primer $5^{\prime}$-ACA CTC CCC ATC CCC ATC TT-3'), and GAPDH (forward primer $5^{\prime}$-GCG AGA TCC CGC TAA CAT CAA ATG G-3'; reverse primer 5'-GCC ATC CAC AGT CTT CTG AGT GGC-3') sequences, with the latter used as a housekeeping gene.

Each PCR was preceded by incubation for $5 \mathrm{~min}$ at $95^{\circ} \mathrm{C}$ to activate Taq-polymerase enzyme and followed by $7 \mathrm{~min}$ at $72^{\circ} \mathrm{C}$ to finish the extension of amplified sequences.

PCR amplification products were separated on $1.5 \%$ agarose gel (BioRad Laboratories, Milan, Italy) stained with GelRed (Biotium Inc., Hayward, CA, USA), visualized by ultraviolet light, acquired by Versadoc (BioRad Laboratories) and analyzed by a densitometry computer programme (ImageJ software v1.44p, $\mathrm{NIH}$, Bethesda, MD, USA).

Western blot. Western blot analyses were performed on rat-isolated hippocampal region ipsilateral to the injection site. Each portion was suspended in ice-cold hypotonic lysis buffer (Tris/ $\mathrm{HCl}$ pH $7.550 \mathrm{mM}, \mathrm{NaCl} 150 \mathrm{mM}$, ethylenediaminetetraacetic acid (EDTA) $1 \mathrm{mM}, 1 \%$ Triton X-100) supplemented with the proper protease inhibitor cocktail (PMSF $1 \mathrm{mM}$, aprotinin $10 \mu \mathrm{g} / \mathrm{ml}$, leupeptin $0,1 \mathrm{mM}$, all from Sigma-Aldrich). After incubation for $40 \mathrm{~min}$ at $+4{ }^{\circ} \mathrm{C}$, homogenates were centrifuged at 14000 r.p.m. for $15 \mathrm{~min}$ and the supernatant removed and stored in aliquots at $-80^{\circ} \mathrm{C}$ until use.

Equivalent amounts $(50 \mu \mathrm{g})$ of each sample calculated by Bradford assay were resolved on $12 \%$ acrylamide SDS-PAGE precast gels (BioRad Laboratories). Proteins were transferred onto nitrocellulose. Membranes were blocked with $5 \%$ w/v no-fat dry milk powder in Tris-buffered saline-Tween 0,1\% (TBS-T) for $1 \mathrm{~h}$ before overnight incubation at $4{ }^{\circ} \mathrm{C}$ with one of the following primary antibodies: rabbit anti-GFAP (1:50000, Abcam plc, Cambridge, UK), rabbit anti-S100B $(1: 1000$, Epitomics, Burlingame, CA, USA), rabbit anti-iNOS $(1: 9000$, Sigma- Aldrich), rabbit anti-COX-2 (1:1000, Cell Signaling Technology, Inc, Danvers, MA, USA), rabbit anti- $\beta$-actin $(1: 1500$, Santa Cruz Biotechnology, Santa Cruz, CA, USA), rabbit anti- $\beta$-catenin $(1: 1000$, Cell Signaling Technology, Inc), rabbit anti-BACE1 (1:1000, Abcam plc), anti-APP (1:1000, Cell Signaling Technology, Inc), rabbit anti-Dkk-1 (1:1000, Santa Cruz Biotechnology), rabbit anti-phosphoGSK3 $\beta$ ([ser9],1: 1000, Cell Signaling Technology, Inc), rabbit antiphospho-tau ([Ser396], 1:500, Novus Biologicals, Littleton, CO, USA), goat antitau (1:500, Santa Cruz Biotechnology). After being extensively washed in TBS-T, membranes were incubated for $1 \mathrm{~h}$ at $25^{\circ} \mathrm{C}$ in the proper secondary horseradish peroxidase-conjugated antibodies (HRP-conjugated goat anti-rabbit IgG, $1: 30000$, Jackson Immunoresearch Europe, Suffolk, UK; HRP-conjugated rabbit anti-goat, 1:5000, Abcam plc). The immunocomplexes were visualized using an 
ECL kit (Amersham, Bucks, UK). Protein expression was quantified by densitometric scanning of the X-ray films with a GS 700 Imaging Densitometer (Bio-Rad laboratories) and a computer programme (ImageJ software).

Enzyme-linked immunosorbent assay. Hippocampal regions ipsilateral to the injection site were homogenized in lysis buffer (Tris- $\mathrm{HCl} \mathrm{pH} 7.520 \mathrm{mM}, \mathrm{NaCl}$ $137 \mathrm{mM}, \mathrm{NP} 401 \%$, glycerol $10 \%$, sodium orthovanadate $0.5 \mathrm{mM}$ ) containing a mix of protease inhibitors (PMSF $1 \mathrm{mM}$, aprotinin $10 \mu \mathrm{g} / \mathrm{ml}$, leupeptin $1 \mu \mathrm{g} / \mathrm{ml}$, all from Sigma-Aldrich), in a 5:1 ratio $\mu$ lysis buffer $/ \mathrm{mg}$ tissue by a mechanical homogenization potter. The homogenates were centrifuged at 14000 r.p.m., at $+4{ }^{\circ} \mathrm{C}$ for $30 \mathrm{~min}$ and the supernatant was immediately used for the assay. The concentrations of S100B, TNF $\alpha$, and IL-1 $\beta$ were measured with commercially available ELISA kit (Invitrogen, Milan, Italy) according to the procedures recommended by the manufacturer. The intensity of the colored product, recorded at $450 \mathrm{~nm}$ with an Epoch Microplate Spectrophotometer (BioTek Instruments, Inc., Winooski, VT, USA), was directly proportional to the concentration of cytokines in the sample.

Immunofluorescence. Extracted brains were transversely cut using a cryostat to obtain coronal sections containing the hippocampal region. Sections (10- $\mu \mathrm{m}$ thickness) were fixed for $4 \mathrm{~min}$ at room temperature with $4 \%$ paraformaldeyde (Merck, Darmstadt, Germany) in $0.12 \mathrm{M}$ phosphate buffer, $\mathrm{pH}$ 7.4. After quenching auto-fluorescence with $0.05 \mathrm{M}$ ammonium chloride, and saturation of non-specific sites with $3 \%$ normal donkey serum (BioCell Research Laboratories, Newport Beach, CA, USA), sections were incubated overnight at $4{ }^{\circ} \mathrm{C}$ with $0.5 \%$ albumin bovine serum $/ 0.25 \%$ Triton-TBS solution containing one of the following primary antibodies: rabbit anti-GFAP (1:500; Abcam plc), rabbit antiS100B (1:1000, BD Transduction Laboratories, San Jose, CA, USA), mouse antiMAP-2 ( $1: 250$, Novus Biologicals). After washing, the sections were incubated with donkey Cy3-labeled anti-rabbit (or anti-mouse) IgG (1:400; Jackson ImmunoResearch Laboratories, West Grove, PA, USA). Negative controls were performed substituting specific Igs with an equivalent amount of non-specific Igs and omitting primary antibodies. After a final wash with PBS, slides were mounted with Vectashield mounting medium, containing DAPI for nuclear staining (Vector Laboratories, Burlingame, CA, USA). Pictures were taken using a fluorescence microscope (Eclipse E600; Nikon Instruments S.p.A., Firenze, Italy). Analysis of signal intensity was measured semiquantitatively in each slice as optical density (OD) and considering the averaged OD of non-immunoreactive regions of the brain for background normalization using a specific computer program (ImageJ software). Because many variables affect the staining intensity of a tissue section, during the acquisition of images, we set the same value of gain and exposure for each channel.

\section{Morris water maze test}

Task procedures: Eighteen days after surgery, rats were handled $1 \mathrm{~min}$ per day for three consecutive days before training on the MWM task. The maze, located in a room containing several visual cues, was a circular tank $1.83 \mathrm{~m}$ in diameter and $0.58 \mathrm{~m}$ in height) filled with water $\left(23-24^{\circ} \mathrm{C}\right)$ to a depth of $20 \mathrm{~cm}$ During the spatial training and reversal learning, a hidden transparent Perspex platform $(20-25 \mathrm{~cm})$ was submerged $2.5 \mathrm{~cm}$ below the surface of the water in the northwest quadrant of the maze. The experiments were performed according to the procedure previously described. ${ }^{68,69}$

Spatial training (acquisition): Days 1-3. Rats were given a daily training session of four trials ( $60 \mathrm{~s}$ each one) for three consecutive days. On each trial, the animal was placed in the tank facing the wall at one of the four designated start positions and allowed to escape onto the hidden platform. If an animal failed to find the platform within $60 \mathrm{~s}$ during the first day of the training, it was manually guided to the platform. The rat was allowed to remain on the platform for $10 \mathrm{~s}$ and was then placed into a holding cage for $25 \mathrm{~s}$ until the start of the next trial. The time each animal spent to reach the platform was recorded as the escape latency.

Probe (memory retention): Day 4. The retention of the spatial training was assessed $24 \mathrm{~h}$ after the last training session. At the probe test, the platform was removed and rats were returned to the water maze for a 60 -s trial. The parameter measured was the time spent by rats to reach the position were the platform was previously located (escape latency).

Reversal learning: Day 5. Rats were given a single training session of five trials (60 s each one); the platform was placed into the quadrant on the opposite side where the platform was previously located. On each trial, the animal was placed in the tank facing the wall at one of the four designated start positions and allowed to escape onto the hidden platform. If an animal failed to find the platform within $60 \mathrm{~s}$ during the first trial, it was manually guided to the platform. The rat was allowed to remain on the platform for $10 \mathrm{~s}$ and was then placed into a holding cage for $15 \mathrm{~s}$ until the start of the next trial. The time each animal spent to reach the platform was recorded as the escape latency.

Behavioral data from the acquisition, probe, and reversal learning were acquired and analyzed using an automated video-tracking system (Smart, Panlab, Harvard Apparatus, Cornellà (Barcelona), Spain). The escape latency for the spatial training and reversal learning working memory, and the amount of time rats spent in the target zone in the probe test were analyzed.

Statistics. Analysis was performed using GraphPad Prism version 4.0 (GraphPad Software, San Diego, CA, USA). Data were analyzed by one or two-way analysis of variance and multiple comparisons were performed using the Bonferroni's post hoc test, when applicable. Data are shown as mean \pm standard error of the mean (S.E.M.) as specified in the figure legends. Differences between mean values were considered statistically significant when $P<0.05$.

\section{Conflict of interest}

The authors declare no conflict of interest.

Acknowledgements. This work was supported by the Italian Ministry of Instruction, University and Research grants (MIUR; PON01-02512 and PRIN2009) to Luca Steardo.

1. Querfurth HW, LaFerla FM. Alzheimer's disease. N Engl J Med 2010; 362: 329-344.

2. Dubois B, Feldman HH, Jacova C, Cummings JL, Dekosky ST, Barberger-Gateau P et al. Revising the definition of Alzheimer's disease: a new lexicon. Lancet Neurol 2010; 9: $1118-1127$.

3. Blennow K, de Leon MJ, Zetterberg H. Alzheimer's disease. Lancet 2006; 368: 387-403.

4. Mrak RE, Griffin WS. Interleukin-1, neuroinflammation, and Alzheimer's disease. Neurobiol Aging 2001; 22: 903-908.

5. Wyss-Coray T. Inflammation in Alzheimer disease: driving force, bystander or beneficial response? Nat Med 2006; 12: 1005-1015.

6. Block ML, Hong JS. Microglia and inflammation-mediated neurodegeneration: multiple triggers with a common mechanism. Prog Neurobiol 2005; 76: 77-98.

7. Verkhratsky A, Rodriguez JJ, Steardo L. Astrogliopathology: a central element of neuropsychiatric diseases? Neuroscientist 3 December 2013; e-pub ahead of print.

8. Fuller S, Steele M, Munch G. Activated astroglia during chronic inflammation in Alzheimer's disease-do they neglect their neurosupportive roles? Mutat Res 2009; 690: 40-49.

9. Medeiros R, LaFerla FM. Astrocytes: conductors of the Alzheimer disease neuroinflammatory symphony. Exp Neurol 2013; 239: 133-138.

10. Esposito G, Scuderi C, Valenza M, Togna GI, Latina V, De Filippis D et al. Cannabidiol reduces Abeta-induced neuroinflammation and promotes hippocampal neurogenesis through PPARgamma involvement. PLoS One 2011; 6: e28668.

11. Cowley TR, O'Sullivan J, Blau C, Deighan BF, Jones R, Kerskens C et al. Rosiglitazone attenuates the age-related changes in astrocytosis and the deficit in LTP. Neurobiol Aging 2012; 33: 162-175.

12. Lo Verme J, Fu J, Astarita G, La Rana G, Russo R, Calignano A et al. The nuclear receptor peroxisome proliferator-activated receptor-alpha mediates the anti-inflammatory actions of palmitoylethanolamide. Mol Pharmacol 2005; 67: 15-19

13. Mackie K, Stella N. Cannabinoid receptors and endocannabinoids: evidence for new players. AAPS J 2006; 8: E298-E306.

14. Cadas $\mathrm{H}$, di Tomaso E, Piomelli D. Occurrence and biosynthesis of endogenous cannabinoid precursor, $\mathrm{N}$-arachidonoyl phosphatidylethanolamine, in rat brain. $\mathrm{J} \mathrm{Neurosci}$ 1997; 17: 1226-1242.

15. Murillo-Rodriguez E, Desarnaud F, Prospero-Garcia O. Diurnal variation of arachidonoylethanolamine, palmitoylethanolamide and oleoylethanolamide in the brain of the rat. Life Sci 2006; 79: 30-37.

16. Skaper SD, Facci L, Romanello S, Leon A. Mast cell activation causes delayed neurodegeneration in mixed hippocampal cultures via the nitric oxide pathway. J Neurochem 1996; 66: 1157-1166.

17. Calignano A, La Rana G, Giuffrida A, Piomelli D. Control of pain initiation by endogenous cannabinoids. Nature 1998; 394: 277-281.

18. Franklin A, Parmentier-Batteur S, Walter L, Greenberg DA, Stella N. Palmitoylethanolamide increases after focal cerebral ischemia and potentiates microglial cell motility. J Neurosci 2003; 23: 7767-7775. 
19. Gatti A, Lazzari M, Gianfelice V, Di Paolo A, Sabato E, Sabato AF. Palmitoylethanolamide in the treatment of chronic pain caused by different etiopathogenesis. Pain Med 2012; 13: $1121-1130$.

20. Keppel Hesselink JM, de Boer T, Witkamp RF. Palmitoylethanolamide: a natural body-own anti-inflammatory agent, effective and safe against influenza and common cold. Int $J$ Inflam 2013; 2013: 151028.

21. LoVerme J, Russo R, La Rana G, Fu J, Farthing J, Mattace-Raso G et al. Rapid broadspectrum analgesia through activation of peroxisome proliferator-activated receptor-alpha. $J$ Pharmacol Exp Ther 2006; 319: 1051-1061.

22. Scuderi C, Valenza M, Stecca C, Esposito G, Carratu MR, Steardo L. Palmitoylethanolamide exerts neuroprotective effects in mixed neuroglial cultures and organotypic hippocampal slices via peroxisome proliferator-activated receptor-alpha. J Neuroinflammation 2012; 9: 49.

23. Scuderi C, Steardo L. Neuroglial roots of neurodegenerative diseases: therapeutic potential of palmitoylethanolamide in models of Alzheimer's disease. CNS Neurol Disord Drug Targets 2013; 12: 62-69.

24. Petrosino S, luvone T, Di Marzo V. N-palmitoyl-ethanolamine: Biochemistry and new therapeutic opportunities. Biochimie 2010; 92: 724-727.

25. Scuderi C, Esposito G, Blasio A, Valenza M, Arietti P, Steardo L Jr. et al. Palmitoylethanolamide counteracts reactive astrogliosis induced by beta-amyloid peptide. J Cell Mol Med 2011; 15: 2664-2674.

26. Verkhratsky A, Parpura V. Recent advances in (patho)physiology of astroglia. Acta Pharmacol Sin 2010; 31: 1044-1054.

27. Verkhratsky A, Sofroniew MV, Messing A, deLanerolle NC, Rempe D, Rodriguez JJ et al. Neurological diseases as primary gliopathies: a reassessment of neurocentrism. ASN Neuro 2012; 4: e00082.

28. Verkhratsky A, Butt AM. Glial Neurobiology United KingdomJohn Wiley and Sons Ltd, 2007.

29. Donato R, Heizmann CW. S100B protein in the nervous system and cardiovascular apparatus in normal and pathological conditions. Cardiovasc Psychiatry Neurol 2010; 2010: 929712

30. Steiner J, Bogerts B, Schroeter ML, Bernstein HG. S100B protein in neurodegenerative disorders. Clin Chem Lab Med 2011; 49: 409-424.

31. Sastre M, Klockgether T, Heneka MT. Contribution of inflammatory processes to Alzheimer's disease: molecular mechanisms. Int J Dev Neurosci 2006; 24: 167-176.

32. Griffin WS. Alzheimer's-Looking beyond plaques. F1000 Med Rep 2011; 3: 24.

33. Ben Menachem-Zidon O, Menahem YB, Hur TB, Yirmiya R. Intra-hippocampal transplantation of neural precursor cells with transgenic over-expression of IL-1 receptor antagonist rescues memory and neurogenesis impairments in an alzheimer's disease model. Neuropsychopharmacology 2013; 39: 401-414.

34. Mrak RE. Neuropathology and the neuroinflammation idea. J Alzheimers Dis 2009; 18 : 473-481.

35. Rojo LE, Fernandez JA, Maccioni AA, Jimenez JM, Maccioni RB. Neuroinflammation: implications for the pathogenesis and molecular diagnosis of Alzheimer's disease. Arch Med Res 2008; 39: 1-16.

36. Frankola KA, Greig NH, Luo W, Tweedie D. Targeting TNF-alpha to elucidate and ameliorate neuroinflammation in neurodegenerative diseases. CNS Neurol Disord Drug Targets 2011; 10: 391-403.

37. Hallenbeck J. How inflammation modulates central nervous system vessel activation and provides targets for intervention-a personal perspective. Ann N Y Acad Sci 2010; 1207: 1-7.

38. Koistinaho J, Malm T, Goldsteins G. Glycogen synthase kinase-3beta: a mediator of inflammation in Alzheimer's disease? Int J Alzheimers Dis 2011; 2011: 129753.

39. Frank-Cannon TC, Alto LT, McAlpine FE, Tansey MG. Does neuroinflammation fan the flame in neurodegenerative diseases? Mol Neurodegener 2009; 4: 47

40. Minghetti L. Cyclooxygenase-2 (COX-2) in inflammatory and degenerative brain diseases. $J$ Neuropathol Exp Neurol 2004; 63: 901-910.

41. Luo Y, Bolon B, Kahn S, Bennett BD, Babu-Khan S, Denis P et al. Mice deficient in BACE1, the Alzheimer's beta-secretase, have normal phenotype and abolished beta-amyloid generation. Nat Neurosci 2001; 4: 231-232.

42. Cole SL, Vassar R. BACE1 structure and function in health and Alzheimer's disease. Curr Alzheimer Res 2008; 5: 100-120.

43. Li Y, Zhou W, Tong Y, He G, Song W. Control of APP processing and Abeta generation level by BACE1 enzymatic activity and transcription. FASEB J 2006; 20: 285-292.

44. Rodrigues EM, Weissmiller AM, Goldstein LS. Enhanced beta-secretase processing alters APP axonal transport and leads to axonal defects. Hum Mol Genet 2012; 21: 4587-4601.

45. Theuns J, Van Broeckhoven C. Transcriptional regulation of Alzheimer's disease genes: implications for susceptibility. Hum Mol Genet 2000; 9: 2383-2394.

46. Gentleman SM, Nash MJ, Sweeting CJ, Graham DI, Roberts GW. Beta-amyloid precursor protein (beta APP) as a marker for axonal injury after head injury. Neurosci Lett 1993; 160 139-144.

47. Caricasole A, Copani A, Caruso A, Caraci F, lacovelli L, Sortino MA et al. The Wnt pathway, cell-cycle activation and beta-amyloid: novel therapeutic strategies in Alzheimer's disease? Trends Pharmacol Sci 2003; 24: 233-238.

48. Inestrosa NC, Montecinos-Oliva C, Fuenzalida M. Wnt signaling: role in Alzheimer disease and schizophrenia. J Neuroimmune Pharmacol 2012; 7: 788-807.
49. Esposito G, Scuderi C, Lu J, Savani C, De Filippis D, luvone T et al. S100B induces tau protein hyperphosphorylation via Dickopff-1 up-regulation and disrupts the Wnt pathway in human neural stem cells. J Cell Mol Med 2008; 12: 914-927.

50. Zenzmaier C, Marksteiner J, Kiefer A, Berger P, Humpel C. Dkk-3 is elevated in CSF and plasma of Alzheimer's disease patients. J Neurochem 2009; 110: 653-661.

51. Cavallini A, Brewerton S, Bell A, Sargent S, Glover S, Hardy C et al. An unbiased approach to identifying tau kinases that phosphorylate tau at sites associated with Alzheimer disease. J Biol Chem 2013; 288: 23331-23347.

52. Hirokawa N. Microtubule organization and dynamics dependent on microtubule-associated proteins. Curr Opin Cell Biol 1994; 6: 74-81.

53. Dehghani L, Hashemi-Beni B, Poorazizi E, Khorvash F, Shaygannejad V, Sedghi M et al. Evaluation of neural gene expression in serum treated embryonic stem cells in Alzheimer's patients. J Res Med Sci 2013; 18(Suppl 1): S20-S23.

54. O'Callaghan JP, Sriram K. Glial fibrillary acidic protein and related glial proteins as biomarkers of neurotoxicity. Expert Opin Drug Saf 2005; 4: 433-442.

55. Donato R, Cannon BR, Sorci G, Riuzzi F, Hsu K, Weber DJ et al. Functions of S100 proteins. Curr Mol Med 2013; 13: 24-57.

56. Blasko I, Veerhuis R, Stampfer-Kountchev M, Saurwein-Teissl M, Eikelenboom P, Grubeck-Loebenstein B. Costimulatory effects of interferon-gamma and interleukin-1beta or tumor necrosis factor alpha on the synthesis of Abeta1-40 and Abeta1-42 by human astrocytes. Neurobiol Dis 2000; 7(6 Pt B): 682-689.

57. Luterman JD, Haroutunian V, Yemul S, Ho L, Purohit D, Aisen PS et al. Cytokine gene expression as a function of the clinical progression of Alzheimer disease dementia. Arch Neurol 2000; 57: 1153-1160.

58. Caricasole A, Copani A, Caraci F, Aronica E, Rozemuller AJ, Caruso A et al. Induction of Dickkopf-1, a negative modulator of the Wnt pathway, is associated with neuronal degeneration in Alzheimer's brain. J Neurosci 2004; 24: 6021-6027.

59. Morris RG. Episodic-like memory in animals: psychological criteria, neural mechanisms and the value of episodic-like tasks to investigate animal models of neurodegenerative disease. Philos Trans R Soc Lond B Biol Sci 2001; 356 1453-1465.

60. Savonenko A, Xu GM, Melnikova T, Morton JL, Gonzales V, Wong MP et al. Episodic-like memory deficits in the APPswe/PS1dE9 mouse model of Alzheimer's disease: relationships to beta-amyloid deposition and neurotransmitter abnormalities. Neurobio Dis 2005; 18: 602-617.

61. Sexton CE, Mackay CE, Lonie JA, Bastin ME, Terriere E, O'Carroll RE et al. MRI correlates of episodic memory in Alzheimer's disease, mild cognitive impairment, and healthy aging. Psychiatry Res 2010; 184: 57-62.

62. Espinosa A, Alegret M, Valero S, Vinyes-Junque G, Hernandez I, Mauleon A et al. A longitudinal follow-up of 550 mild cognitive impairment patients: evidence for large conversion to dementia rates and detection of major risk factors involved. J Alzheimers Dis 2012; 34: 769-780

63. Paxinos G, Watson C. The Rat Brain In Stereotaxic Coordinates, 2007

64. Duran-Gonzalez J, Michi ED, Elorza B, Perez-Cordova MG, Pacheco-Otalora LF Touhami $\mathrm{A}$ et al. Amyloid beta peptides modify the expression of antioxidant repair enzymes and a potassium channel in the septohippocampal system. Neurobiol Aging 2013; 34: 2071-2076.

65. De Felice FG, Wu D, Lambert MP, Fernandez SJ, Velasco PT, Lacor PN et al. Alzheimer's disease-type neuronal tau hyperphosphorylation induced by A beta oligomers Neurobiol Aging 2008; 29: 1334-1347.

66. Sheerin AH, Zhang X, Saucier DM, Corcoran ME. Selective antiepileptic effects of $\mathrm{N}$-palmitoylethanolamide, a putative endocannabinoid. Epilepsia 2004; 45: 1184-1188.

67. Kapoor A, Collino M, Castiglia S, Fantozzi R, Thiemermann C. Activation of peroxisome proliferator-activated receptor-beta/delta attenuates myocardial ischemia/reperfusion injury in the rat. Shock 2010; 34: 117-124.

68. Koistinaho M, Ort M, Cimadevilla JM, Vondrous R, Cordell B, Koistinaho J et al. Specific spatial learning deficits become severe with age in beta -amyloid precursor protein transgenic mice that harbor diffuse beta -amyloid deposits but do not form plaques. Proc Natl Acad Sci USA 2001; 98: 14675-14680.

69. Campolongo P, Ratano P, Ciotti MT, Florenzano F, Nori SL, Marolda R et al. Systemic administration of substance $p$ recovers Beta amyloid-induced cognitive deficits in rat: involvement of kv potassium channels. PLoS One 2013; 8: e78036.

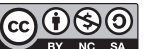

Cell Death and Disease is an open-access journal published by Nature Publishing Group. This work is licensed under a Creative Commons Attribution-NonCommercialShareAlike 3.0 Unported License. The images or other third party material in this article are included in the article's Creative Commons license, unless indicated otherwise in the credit line; if the material is not included under the Creative Commons license, users will need to obtain permission from the license holder to reproduce the material. To view a copy of this license, visit http://creativecommons.org/licenses/ by-nc-sa/3.0/ 